\title{
What factors may contribute to sex differences in childhood obesity prevalence in China?
}

\author{
Vivian HC Wang ${ }^{1}$, Jungwon Min ${ }^{2}$, Hong Xue ${ }^{3}$, Shufa Du ${ }^{4}$, Fei Xu ${ }^{5,6}$, Huijun Wang ${ }^{7}$ and \\ Youfa Wang $2,8, *$ \\ ${ }^{1}$ The Robert F. Wagner Graduate School of Public Service, New York University, New York, NY, USA: ${ }^{2}$ Systems- \\ oriented Global Childhood Obesity Intervention Program, Fisher Institute of Health and Well-being, College of \\ Health, Ball State University, Muncie, IN, USA: ${ }^{3}$ Department of Health Behavior and Policy, School of Medicine, \\ Virginia Commonwealth University, Richmond, VA, USA: ${ }^{4}$ Carolina Population Center, University of North Carolina, \\ Chapel Hill, NC, USA: ${ }^{5}$ Nanjing Municipal Center for Disease Control and Prevention, Nanjing, People's Republic \\ of China: ${ }^{6}$ Department of Epidemiology and Biostatistics, School of Public Health, Nanjing Medical University, \\ Nanjing, People's Republic of China: ${ }^{7}$ National Institute for Nutrition and Health, Chinese Center for Disease Control \\ and Prevention, Beijing, People's Republic of China: ${ }^{8}$ Department of Nutrition and Health Sciences, College of \\ Health, Ball State University, Office: HP 302, Muncie, IN 47306, USA
}

Submitted 6 June 2017: Final revision received 18 January 2018: Accepted 25 January 2018: First published online 26 February 2018

\begin{abstract}
Objective: Previous studies in China showed large sex differences in childhood overweight and obesity (OW/OB) rates. However, limited research has examined the cause of these sex differences. The present study aimed to examine individual and parental/familial factors associated with sex differences in childhood OW/OB rates in China.

Design: Variables associated with child weight status, beliefs and behaviours, and obesity-related parenting practices were selected to examine their sex differences and association with a sex difference in child OW/OB outcomes using logistic regression analysis.

Setting: Cross-sectional data analysis using the 2011 China Health and Nutrition Survey. Subjects: Children aged 6-17 years ( $n$ 1544) and their parents.

Results: Overall child OW/OB prevalence was 16.8\%. Adolescent boys (AB; 12-17 years) were about twice as likely to be overweight/obese as adolescent girls (AG; $15.5 v .8 .4 \%, P<0.05$ ). AB more likely had energy intake exceeding recommendations, self-perceived underweight, underestimated their body weight and were satisfied with their physical activity level than AG. AG more likely practised weight-loss management through diet and self-perceived overweight than AB. Mothers more likely identified AG's weight accurately but underestimated AB's weight. Stronger associations with risk of childhood OW/OB were found in boys than girls in dieting to lose weight (OR=6.7 in boys $v .2 .6$ in girls) and combined maternal and child perception of the child's overweight ( $\mathrm{OR}=35.4$ in boys $v .14 \cdot 2$ in girls).

Conclusions: Large sex differences in childhood obesity may be related to the sex disparities in weight-related beliefs and behaviours among children and their parents in China.
\end{abstract}

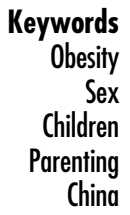

Over the past three decades, the prevalence of overweight and obesity (OW/OB) has increased steadily worldwide, including in China. At present, over $40 \%$ of adults worldwide are overweight or obese ${ }^{(1)}$. Recently, the WHO called for an international effort to end the global childhood obesity epidemic ${ }^{(2)}$. Whereas childhood OW/OB in some developed countries such as the USA is reported to have stabilized since in recent years ${ }^{(3)}$, in developing countries the prevalence of childhood OW/OB has increased more rapidly, including China ${ }^{(4)}$. The study by Sun et al. showed a steady increase of approximately one percentage point rate annually based on a national survey $^{(5)}$. A nationally representative school-based survey showed a higher prevalence of childhood obesity among populations of higher socio-economic status (SES) in an urban area, compared with populations of lower SES in a rural area, for both boys $(13.0 \mathrm{v} .1 \cdot 3 \%)$ and girls $(6 \cdot 8 v \cdot 0 \cdot 8 \%)^{(6)}$. 
Lifestyle in China has been redefined through rapid economic developments with the influx of wealth and resources, affecting dietary patterns, means of transportation, and social norms and values. The risk factors for developing obesity as a result of socio-economic change are similar in many developing countries. While these socio-economic risks are commonly observed in overweight and obese populations among many developing countries, research has shown a unique pattern of large sex differences in childhood OW/OB rates in China, but not in other developing countries. Specifically, Chinese boys are almost twice as likely as girls to be overweight or obese. In 2010, a large nationally representative survey of school-aged children reported that $19.0 \%$ of boys and $10.9 \%$ of girls were overweight or obese $^{(7)}$.

A good understanding of the factors that contribute to the sex differences will help guide intervention efforts. Sex differences in genetic expression and sex-specific physical outcomes are self-evident, but the sex differences in acquired behaviours and perceptions vary across cultures and their influence on childhood obesity remains unclear. Research has shown that girls naturally require less energy intake than boys on a biological level ${ }^{(8)}$. On a behavioural level, girls report being more attentive to food and its effects on health and weight control ${ }^{(9)}$. On a psychological level related to body image, girls self-perceive as overweight more often than do boys, including Chinese children $^{(10,11)}$.

Previous research from China indicates that childhood weight perception, body image and parenting differ by child sex ${ }^{(11-13)}$. Chinese parents also perceive their children's weight differently by child sex ${ }^{(12)}$. While no studies have systematically investigated the risk factors to explain the sex differences in OW/OB rates among children in China, using recently collected nationwide survey data we comprehensively examined sex differences in OW/OB rates by comparing childhood weight-related behaviours and beliefs, and maternal perception of child weight status and related behaviours, between boys and girls while considering sociodemographic characteristics.

\section{Methods}

\section{Overview of study design}

We used the data from the China Health and Nutrition Survey (CHNS) to examine risk factors that might help explain the sex differences in childhood OW/OB-related measures with a cross-sectional study design, using the most recent data from 2011. The CHNS is a multipurpose longitudinal survey conducted since 1989 and now covers nine provinces and three megacities in China. Although the CHNS is not designed to be nationally representative, it covers areas that account for approximately $45 \%$ of China's total population varying substantially in geography, economic development, public resources and health indicators. The 4400 sampled households with a total of 26000 individuals were selected based on income level and random selection of urban and rural communities and rural villages in each county. The questionnaire focused on examining various socio-economic factors and people's health and nutritional status in China. All participants, including children and their mothers, were required to provide a written informed consent for their participation before they could proceed with the study. More detailed information about the CHNS is provided elsewhere ${ }^{(14)}$.

For the present study, we selected variables using a conceptual framework we developed based on the Dietary Guidelines for Americans' Socio-ecological Framework for Nutrition and Physical Activity Decisions ${ }^{(15)}$. The framework describes children's environment with three levels, each of which suggests varied influences on decisions around food intake and physical activity: individual, parental and familial levels. Factors on the individual level include weight-related behaviours, beliefs and biology. Parental and familial level include SES, parental weight status, and parental perception of the child's weight status and weight-related behaviours. The selected variables were incorporated to explore the sex differences in childhood obesity rates in China. The present study was approved by the University at Buffalo Institutional Review Board.

\section{Study subjects}

Children aged 6 to 17 years ( $n$ 1544) and their mothers were included in the current study. A total of 2374 children aged 6-17 years were surveyed for the year 2011 and 35\% of the children were eliminated due to missing and implausible values for sex, weight, height and total energy intake. The missing values may be due to the following reasons: (i) participants were unavailable on the physical examination day; or (ii) the person doing data entry could not recognize the figures that health workers/interviewers recorded. We also eliminated outliers based on the ranges of plus or minus three standard deviations from the means of weight, height and total energy intake. Mothers represented parents to answer selected family-related questions, including those on parental perceptions of child's weight-related behaviours and beliefs.

\section{Measures and key study variables}

\section{Classification of childhood overweight, obesity and central obesity}

We assessed child weight status and BMI $Z$-score. In CHNS, anthropometrics of the subjects were measured by trained health workers. BMI was calculated and used to classify children's weight status as normal weight, overweight or obese using the 2000 International Obesity Task Force BMI cut-off points ${ }^{(16)}$. Sex- and age-specific BMI $Z$-scores were calculated using the US Centers for Disease Control and Prevention growth chart as a comparison ${ }^{(17)}$. 
Such data specifically for the population in China that allow calculation of BMI $Z$-scores were not available at the time of data analysis.

Children's weight-related behaviours, beliefs and perception We identified six variables to represent weight-related behaviours, beliefs and perception: (i) total energy intake based on the average of $24 \mathrm{~h}$ dietary recalls conducted on three consecutive days (two weekdays and one weekend day). All individuals aged 12 years or older provided the dietary recall data by themselves. Mothers or caregivers of children who fed or took care of children younger than 12 years provided the data for them. Food models and food pictures were also used to help participants estimate the amount of food consumed. In addition to the individual dietary recalls, the health workers measured all food items in inventories and compared individual recalls against the inventories. More details on the approach for comparison can be found in a related article ${ }^{(18)}$. The individual total energy intake was compared with the sex- and age-specific 2013 Chinese Dietary Recommended Intake ${ }^{(19)}$; (ii) frequency of sugar-sweetened beverage intake was asked as 'almost every day', '3-4 times a week', 'once or twice a week', 'once or twice a month' and 'no more than once a month'. In the present study we consolidated the categories as often ( $\geq 3$ drinks/week) and less often ( $\leq 2$ drinks/week); (iii) sedentary activity was indicated by the daily average number of hours spent watching television (TV) for most of the study subjects who responded to the survey question. For comparisons, we categorized daily TV time into: $<1 \mathrm{~h}, 1-2 \mathrm{~h}$ and $\geq 2 \mathrm{~h}$; (iv) daily sleep duration was classified using $\geq 9 \mathrm{~h}$ as the cutoff point ${ }^{(20)}$; (v) weight management was assessed through diet control in the previous year to 'gain weight', 'lose weight' or 'do nothing'; and (vi) children were asked whether they thought they were 'underweight', 'normal weight' or 'overweight' to report their self-perception of weight status.

Maternal weight status and perceptions of their children Due to some survey questions asking only the mother, to be consistent, maternal data were representative of the parental level in the present study. Maternal weight status was classified using Chinese BMI cut-off points for overweight $\left(\geq 24\right.$ and $\left.<28 \mathrm{~kg} / \mathrm{m}^{2}\right)$ and obesity $\left(\geq 28 \mathrm{~kg} / \mathrm{m}^{2}\right)^{(21)}$.

Mothers were asked to choose: (i) whether they perceived their child's weight status as underweight, normal weight or overweight; (ii) whether they were involved in their child's weight control-related behaviors as encouraging the child's weight change through diet or not; and (iii) whether they perceived their child's physical activity level as 'too little', 'too much' or 'just the right amount'.

To examine the effect of child weight status on child and maternal perception of the child's weight, we included variables comparing their individual perceptions (i.e. 'consistent', 'underestimated' and 'overestimated') and child-mother paired perception (i.e. 'overweight by both', 'non-overweight by both' and 'disagreed with each other') with the child's actual weight status.

\section{Socio-economic status and residence area}

The SES included parental education level and household income. Completion of secondary education for parents was used as a cut-off point: education up to high school $v$. college or higher degree. Household income level was categorized in tertiles: low, medium or high income. Urban/rural residence area, which is known to be associated with the level of access to food and physical activity, was also considered ${ }^{(14)}$.

\section{Statistical analysis}

First, we compared the children's BMI $Z$-score and weight status between girls and boys stratified by child age group, maternal education and weight status, household income and urban/rural residence. Then, we examined sex differences in children's weight-related behaviours, including energy intake, sugar-sweetened beverage consumption, diet control to manage weight, daily sleep duration and daily TV viewing time. Next, we examined sex differences in children's self-perceived weight, maternal perception of her child's weight and the comparison of the perceptions with the children's actual body weight using weight status established by the 2000 International Obesity Task Force BMI cut-off points. The $t$ test and the $\chi^{2}$ test were used to assess sex differences and displayed with means and SD or percentage.

Finally, using separate logistic regression models, we estimated sex differences in the association between OW/ $\mathrm{OB}$ and each of the risk factors found to vary by child sex in the earlier analyses of child weight-related behaviors and beliefs and maternal weight status and perception of child weight with marginally statistical significance $(P<0 \cdot 1)$ after adjusting for obesity-related sociodemographics. OR and $95 \%$ CI were reported.

Data management and analyses were conducted using the statistical software packages Stata version 15 and SAS version 9.3 .

\section{Results}

\section{Subjects' characteristics}

Of the 1544 children aged $6-17$ years, about half were girls and $40.9 \%$ were adolescents ( $n$ 631; aged $12-17$ years). Age distributions were similar for girls and boys. More boys than girls $(33.5 v \cdot 29 \cdot 5 \%, P=0.013)$ lived in the rural area. Fifteen per cent of the mothers had a bachelor's or higher degree. The median monthly household income was 35549 RMB (Renminbi, or Chinese Yuan), equivalent to roughly \$US $5356.51(1 \mathrm{RMB}=\$ \mathrm{UD} 0.15$ as of 2017 ). 


\section{Sex differences in child BMI Z-score and overweight/obesity rates}

Mean BMI $Z$-score was $0 \cdot 18$ (sD 1.46) for boys and $-0 \cdot 11$ (SD 1.25) for girls. One in six children was overweight or obese (OW/OB) and about 5\% were obese. Boys had higher BMI $Z$-scores and prevalence of OW/OB using the International Obesity Task Force definition (19.5 v. 14.0\%) than girls (all $P<0 \cdot 01$; Table 1 ).

Sex differences in BMI $Z$-score and OW/OB varied by individual, parental and familial characteristics. Adolescent boys (12-17 years) were about twice as likely to be OW/ OB as girls (15.5 v. 8.4\%), which was not observed among the younger children aged 6-11 years. Among those children who lived in urban areas and whose mothers were OW/OB, boys had significantly higher OW/OB rate than girls. Yet, children who lived in rural areas and children with non-OW/OB mothers did not have significant sex difference in child weight status. Regarding SES, boys were more likely than girls to be OW/OB if their mothers held up to a high-school degree, but the likelihood of being OW/OB was not significantly different for both girls and boys if their mothers had a college degree or higher.

\section{Sex differences in child weight-related behaviours, and maternal/child perception of child weight status and obesity-related behaviours}

Table 2 shows sex differences in individual dietary and weight-related behaviours. There were sex differences in some behaviours, but inconsistent by age group. Overall, about one in three children exceeded the energy intake recommended by the Chinese standard; adolescent boys were more likely than adolescent girls to consume energy higher than recommended $(39.5 v .30 \cdot 0 \%, P=0 \cdot 01)$ and young boys were more likely than young girls to drink sugar-sweetened beverages (24.7 v. 19.1\%, $P=0.05)$.

On the other hand, adolescent girls were less likely to sleep for $\geq 9$ h daily (31.9v. $40.9 \%, P=0.02)$ but three times more likely to modify their diet for weight loss than boys ( $14.9 v .4 \cdot 1 \%$ ). Less than $10 \%$ of children watched TV for $\geq 2 \mathrm{~h} / \mathrm{d}$ and no sex difference was shown in daily TV viewing time regardless of age.

Children's and their mothers' perception of child weight status and children's weight-related behaviors are compared by sex in Table 3. Adolescents and their mothers had significant sex differences in perceptions of adolescent weight status. Adolescent boys were about twice more likely to self-perceive underweight (23.3 v. 12.8\%) and underestimate their body weight (23.9 v. 9.4\%) than girls, while girls were more likely to overestimate their weight than boys (29.6 v. 11.0\%). We observed a similar sex difference in maternal perception of the child weight status. Boys' mothers were more likely to perceive underweight $(23.3 v$ v. 13.8\%) and underestimate the child's weight status $(24.4 v .10 \cdot 3 \%)$ than girls' mothers, while girls' mothers were more likely to have a correct perception of the child's weight status than boys' mothers

Table 1 Sex differences in BMI Z-score and combined prevalence of childhood overweight and obesity (OW/OB) in Chinese children ( $n$ 1544) by age group, socio-economic status and maternal weight status: the 2011 China Health and Nutrition Survey (CHNS)

\begin{tabular}{|c|c|c|c|c|c|c|c|c|c|}
\hline & \multirow[b]{3}{*}{$n \S$} & \multicolumn{5}{|c|}{ BMI Z-score } & \multicolumn{3}{|c|}{ OW/OB } \\
\hline & & \multicolumn{2}{|c|}{ Boys } & \multicolumn{2}{|c|}{ Girls } & \multirow[b]{2}{*}{$P \|$} & \multirow{2}{*}{$\frac{\text { Boys }}{\%}$} & \multirow{2}{*}{$\frac{\text { Girls }}{\%}$} & \multirow[b]{2}{*}{$P \|$} \\
\hline & & Mean & SD & Mean & SD & & & & \\
\hline All & 1544 & 0.18 & 1.46 & -0.11 & 1.25 & $<0.001$ & 19.5 & 14.0 & $<0.01$ \\
\hline \multicolumn{10}{|l|}{ Age group } \\
\hline $6-11$ years & 913 & 0.33 & 1.60 & -0.04 & 1.38 & $<0.001$ & $22 \cdot 3$ & $17 \cdot 7$ & 0.086 \\
\hline $12-17$ years & 631 & -0.04 & $1 \cdot 19$ & -0.20 & 1.01 & 0.05 & $15 \cdot 5$ & 8.4 & $<0.01$ \\
\hline \multicolumn{10}{|l|}{ Maternal weight status } \\
\hline Underweight & 58 & -0.40 & 1.75 & -0.76 & 1.35 & 0.38 & $12 \cdot 0$ & $12 \cdot 1$ & 0.98 \\
\hline Normal weight & 704 & 0.04 & 1.40 & -0.14 & 1.27 & 0.07 & $16 \cdot 5$ & 13.9 & 0.33 \\
\hline Overweight or obese & 427 & 0.56 & 1.45 & 0.20 & 1.17 & $<0.01$ & $26 \cdot 9$ & $17 \cdot 8$ & 0.02 \\
\hline \multicolumn{10}{|l|}{ Maternal education } \\
\hline Up to high school degree & 1029 & $0 \cdot 11$ & 1.48 & -0.14 & 1.24 & $<0.01$ & $18 \cdot 3$ & $13 \cdot 1$ & 0.02 \\
\hline College or higher & 189 & 0.73 & $1 \cdot 15$ & 0.34 & 1.26 & 0.02 & $30 \cdot 4$ & $23 \cdot 7$ & 0.29 \\
\hline \multicolumn{10}{|l|}{ Household income tertiles } \\
\hline Low & 528 & $0 \cdot 10$ & 1.50 & -0.25 & 1.26 & $<0.01$ & 18.9 & $11 \cdot 2$ & 0.01 \\
\hline Medium & 503 & 0.07 & 1.44 & -0.19 & $1 \cdot 17$ & 0.02 & $15 \cdot 8$ & 10.9 & $0 \cdot 10$ \\
\hline High & 484 & 0.34 & 1.40 & 0.14 & 1.27 & 0.09 & 23.2 & $20 \cdot 4$ & 0.45 \\
\hline \multicolumn{10}{|l|}{ Urban/rural residence } \\
\hline Urban & 572 & 0.34 & 1.39 & 0.01 & $1 \cdot 17$ & $<0.01$ & 24.0 & $15 \cdot 1$ & $<0.01$ \\
\hline Rural & 972 & $0 \cdot 10$ & 1.48 & -0.18 & 1.30 & $<0.01$ & $17 \cdot 2$ & $13 \cdot 2$ & 0.08 \\
\hline
\end{tabular}

†Sex- and age-specific BMI Z-scores were calculated using the US Centers for Disease Control and Prevention growth charts ${ }^{(17)}$. ҒOW/OB is the combined prevalence of overweight and obesity, based on the 2000 International Obesity Task Force BMI cut-off points $^{(16)}$.

§The sample size differs by variable due to missing data.

$\| P$ value indicates the sex difference by the $\chi^{2}$ test or $t$ test; significant $P$ values are indicated in bold.

TMaternal weight status is based on the Chinese BMl cut-off points for overweight $\left(\geq 24\right.$ and $\left.<28 \mathrm{~kg} / \mathrm{m}^{2}\right)$ and obese status $\left(\geq 28 \mathrm{~kg} / \mathrm{m}^{2}\right)$ in adults $^{(21)}$. 
Table 2 Sex differences in weight-related behaviours of Chinese children ( $n$ 1544)† by age group: the 2011 China Health and Nutrition Survey (CHNS)

\begin{tabular}{|c|c|c|c|c|c|c|c|c|}
\hline & \multicolumn{4}{|c|}{ Aged 6-11 years } & \multicolumn{4}{|c|}{ Aged $12-17$ years } \\
\hline & All $(\%)$ & Boys (\%) & Girls (\%) & $P \ddagger$ & All $(\%)$ & Boys (\%) & Girls (\%) & $P \ddagger$ \\
\hline \multicolumn{9}{|l|}{ Total energy intake (n 1477) } \\
\hline Exceeded DRI recommendation§ & $30 \cdot 4$ & $31 \cdot 3$ & $29 \cdot 5$ & 0.55 & 34.9 & 39.5 & $30 \cdot 0$ & 0.01 \\
\hline \multicolumn{9}{|c|}{ Sugar-sweetened beverage consumption ( $n$ 1377) } \\
\hline Often ( $\geq 3$ drinks/week) & $22 \cdot 0$ & $24 \cdot 7$ & $19 \cdot 1$ & 0.05 & $27 \cdot 9$ & $30 \cdot 6$ & $25 \cdot 0$ & 0.14 \\
\hline Less often ( $\leq 2$ drinks/week) & $78 \cdot 0$ & $75 \cdot 3$ & $80 \cdot 9$ & & $72 \cdot 1$ & $69 \cdot 4$ & $75 \cdot 0$ & \\
\hline \multicolumn{9}{|l|}{ Television time (daily; $n$ 1430) } \\
\hline$<1 \mathrm{~h}$ & $27 \cdot 5$ & $27 \cdot 3$ & $27 \cdot 6$ & 0.97 & $48 \cdot 3$ & $49 \cdot 7$ & $46 \cdot 9$ & 0.70 \\
\hline $1-2 \mathrm{~h}$ & $63 \cdot 2$ & $63 \cdot 6$ & $63 \cdot 0$ & & $46 \cdot 2$ & 44.5 & $48 \cdot 0$ & \\
\hline$\geq 2 h$ & $9 \cdot 3$ & $9 \cdot 1$ & $9 \cdot 4$ & & 5.5 & $5 \cdot 8$ & $5 \cdot 1$ & \\
\hline \multicolumn{9}{|l|}{ Daily sleep duration (n 1525) } \\
\hline$<9 \mathrm{~h}$ & $19 \cdot 9$ & $21 \cdot 6$ & $18 \cdot 2$ & 0.19 & 63.5 & $59 \cdot 1$ & $68 \cdot 1$ & 0.02 \\
\hline$\geq 9 \mathrm{~h}$ & $80 \cdot 1$ & $78 \cdot 4$ & $81 \cdot 8$ & & 36.5 & 40.9 & 31.9 & \\
\hline \multicolumn{9}{|c|}{ Diet change to manage weight in the previous year ( $n$ 1497) } \\
\hline Nothing & $91 \cdot 2$ & $91 \cdot 1$ & $91 \cdot 3$ & 0.994 & $86 \cdot 1$ & $90 \cdot 9$ & $81 \cdot 1$ & $<0.001$ \\
\hline To lose weight & $5 \cdot 6$ & $5 \cdot 7$ & 5.5 & & $9 \cdot 4$ & $4 \cdot 1$ & 14.9 & \\
\hline To gain weight & $3 \cdot 2$ & $3 \cdot 2$ & $3 \cdot 2$ & & $4 \cdot 5$ & $5 \cdot 0$ & $4 \cdot 0$ & \\
\hline
\end{tabular}

DRI, Dietary Recommended Intake.

†The sample size differs by variable due to missing data.

$\ddagger P$ value indicates the sex difference by the $\chi^{2}$ test; significant $P$ values are indicated in bold.

$\S D R I$ for daily energy intake is sex- and age-specific, based on the Chinese DRIs Handbook, 2013 version $^{(19)}$.

Table 3 Sex differences in children's and maternal perception of the child's weight status and related behaviours among Chinese children ( $n$ 1544) by age group: the 2011 China Health and Nutrition Survey (CHNS)

\begin{tabular}{|c|c|c|c|c|c|c|c|c|}
\hline & \multicolumn{4}{|c|}{ Aged $6-11$ years } & \multicolumn{4}{|c|}{ Aged $12-17$ years } \\
\hline & All $(\%)$ & Boys (\%) & Girls (\%) & $P+$ & All $(\%)$ & Boys (\%) & Girls (\%) & $P \dagger$ \\
\hline \multicolumn{9}{|c|}{ Self-perception of body weight ( $n$ 1468) } \\
\hline Underweight & $22 \cdot 3$ & $22 \cdot 9$ & $21 \cdot 6$ & \multirow[t]{3}{*}{$0 \cdot 212$} & $18 \cdot 2$ & $23 \cdot 3$ & $12 \cdot 8$ & \multirow[t]{3}{*}{$<0.001$} \\
\hline Normal weight & $66 \cdot 2$ & 63.9 & $68 \cdot 7$ & & $63 \cdot 6$ & $64 \cdot 1$ & $63 \cdot 0$ & \\
\hline Overweight & 11.5 & 13.2 & $9 \cdot 7$ & & $18 \cdot 2$ & 12.6 & $24 \cdot 2$ & \\
\hline \multicolumn{9}{|c|}{ Child self-perception $v$. actual body weight ( $n$ 1468) } \\
\hline Consistent & $61 \cdot 6$ & 63.4 & $59 \cdot 6$ & \multirow[t]{3}{*}{0.26} & $63 \cdot 1$ & $65 \cdot 1$ & 60.9 & \multirow[t]{3}{*}{$<0.001$} \\
\hline Underestimated & $25 \cdot 3$ & $25 \cdot 2$ & $25 \cdot 4$ & & $16 \cdot 9$ & 23.9 & 9.4 & \\
\hline Overestimated & $13 \cdot 1$ & 11.4 & $15 \cdot 0$ & & $20 \cdot 0$ & $11 \cdot 0$ & $29 \cdot 6$ & \\
\hline \multicolumn{9}{|c|}{ Maternal perception of the child's weight ( $n$ 1147) } \\
\hline Underweight & 28.6 & $28 \cdot 1$ & $29 \cdot 2$ & \multirow[t]{3}{*}{0.39} & $18 \cdot 8$ & $23 \cdot 3$ & $13 \cdot 8$ & \multirow[t]{3}{*}{0.01} \\
\hline Normal weight & $59 \cdot 5$ & $58 \cdot 3$ & $60 \cdot 7$ & & $70 \cdot 6$ & $68 \cdot 2$ & $73 \cdot 3$ & \\
\hline Overweight & 11.9 & 13.6 & $10 \cdot 1$ & & $10 \cdot 6$ & 8.5 & $12 \cdot 9$ & \\
\hline \multicolumn{9}{|c|}{ Maternal perception $v$. child's actual body weight ( $n$ 1147) } \\
\hline Consistent & $60 \cdot 4$ & $60 \cdot 1$ & $60 \cdot 7$ & \multirow[t]{3}{*}{0.97} & $69 \cdot 8$ & $67 \cdot 4$ & $72 \cdot 4$ & \multirow[t]{3}{*}{$<0.001$} \\
\hline Underestimated & $29 \cdot 2$ & $29 \cdot 6$ & $28 \cdot 8$ & & $17 \cdot 8$ & 24.4 & $10 \cdot 3$ & \\
\hline Overestimated & $10 \cdot 4$ & $10 \cdot 3$ & 10.5 & & 12.4 & 8.2 & $17 \cdot 2$ & \\
\hline \multicolumn{9}{|c|}{ Self- and maternal perception of the child's body weight ( $n$ 1097) } \\
\hline Overweight by both & 8.8 & $11 \cdot 0$ & 6.5 & \multirow[t]{3}{*}{0.11} & 8.9 & $6 \cdot 6$ & $11 \cdot 6$ & \multirow[t]{3}{*}{$<0.01$} \\
\hline Non-overweight by both & 84.5 & 83.2 & $86 \cdot 0$ & & $80 \cdot 3$ & $85 \cdot 6$ & $74 \cdot 2$ & \\
\hline Disagreed with each other & 6.7 & $5 \cdot 8$ & 7.5 & & $10 \cdot 8$ & $7 \cdot 8$ & $14 \cdot 2$ & \\
\hline \multicolumn{9}{|c|}{ Maternal perception of child's physical activity level ( $n$ 1083) } \\
\hline Too little & $39 \cdot 2$ & $39 \cdot 7$ & 38.6 & \multirow[t]{3}{*}{0.77} & $45 \cdot 6$ & 43.9 & 47.5 & \multirow[t]{3}{*}{0.21} \\
\hline Too much & $7 \cdot 4$ & $8 \cdot 0$ & $6 \cdot 8$ & & 3.9 & $5 \cdot 3$ & $2 \cdot 3$ & \\
\hline Just the right amount & 53.4 & $52 \cdot 3$ & $54 \cdot 6$ & & 50.5 & $50 \cdot 8$ & $50 \cdot 2$ & \\
\hline \multicolumn{9}{|c|}{$\begin{array}{l}\text { Maternal encouragement to manage weight through diet change } \\
(n 1150)\end{array}$} \\
\hline No & $71 \cdot 1$ & $67 \cdot 9$ & $74 \cdot 3$ & \multirow[t]{2}{*}{0.07} & $79 \cdot 2$ & 79.5 & 78.9 & \multirow[t]{2}{*}{0.22} \\
\hline Yes & $28 \cdot 9$ & $32 \cdot 1$ & $25 \cdot 7$ & & $20 \cdot 8$ & 20.5 & $21 \cdot 1$ & \\
\hline
\end{tabular}

$\dagger P$ value indicates the sex difference by the $\chi^{2}$ test; significant $P$ values are indicated in bold.

(72.4 v. 67.4\%). Additionally, adolescent girls were more likely than adolescent boys to self-perceive and to be perceived by their mothers as overweight (11.6 v. 6.6\%, $P<0.01)$. We found no sex differences in these trends described above among the younger children.
Sex differences in the associations of individual, parental and familial factors with the risk of childbood overweight/obesity

We present sex-specific OR for the association of each risk factor with childhood OW/OB and the sex difference in the 
Table 4 Association of individual and familial risk factors with childhood overweight/obesity (OW/OB) in Chinese children ( $n$ 1544)†: the 2011 China Health and Nutrition Survey

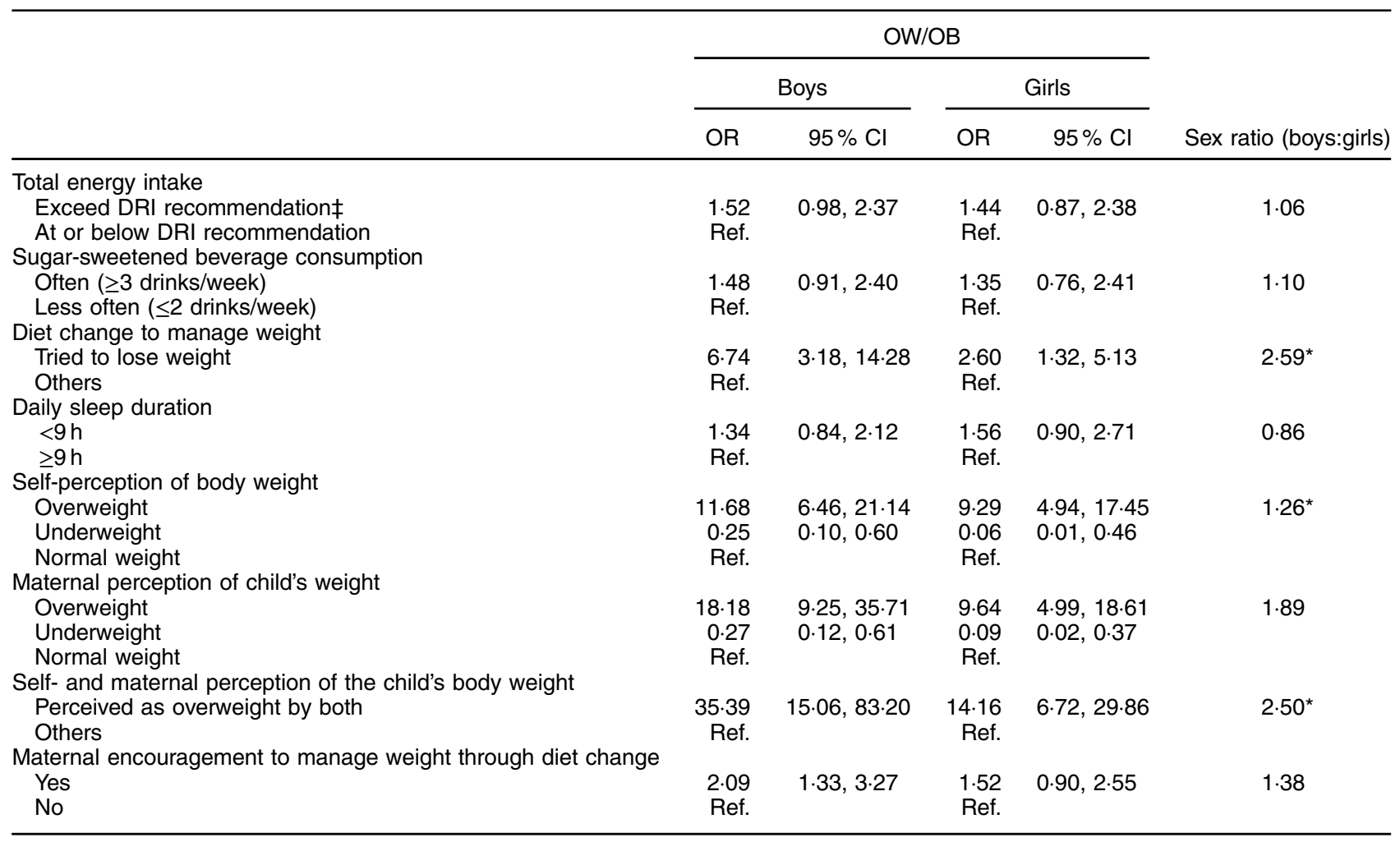

DRI, Dietary Recommended Intake; Ref., reference category.

${ }^{*} P<0.05$, indicating significant interactions between sex and each of the risk factors on the risk of OW/OB in logistic regression analysis.

†Logistic regression models were fit separately for boys and girls and each of the eight variables having marginally significant sex difference $(P<0.1)$ from Tables 2 and 3 after adjusting for child age, maternal education and weight status, household income and urban/rural residence area.

fDRI for daily energy intake is sex- and age-specific, based on the Chinese DRIs Handbook, 2013 version ${ }^{(19)}$.

association indicated by sex ratio in Table 4. After adjusting for child age, maternal education and weight status, household income and urban/rural residence, boys' and girls' diet change to manage weight and their maternal weight perception of the child were significant risk factors of childhood OW/OB.

Comparing the effect sizes, boys had a stronger association between risk factors and childhood OW/OB than girls, including diet change to manage weight $(\mathrm{OR}=6.74 v .2 \cdot 60)$, self-perceived overweight $(\mathrm{OR}=11.68 v \cdot 9 \cdot 29)$, perceived overweight by the mother $(\mathrm{OR}=18 \cdot 18 v$.9.64), self- and maternal perception of child's overweight $(\mathrm{OR}=35.39 v$. 14.16) and maternal encouragement to change diet through weight management $(\mathrm{OR}=2.09 v .1 .52)$. We found a significant interaction between sex and several individual and familial risk factors associated with childhood OW/OB: diet change to manage weight, child's self-perception of body weight and combined maternal and child perception of the child's overweight.

\section{Discussion}

Using nationwide survey data in China to explore sex differences in factors associated with childhood OW/OB, we found that adolescent boys were more likely to be
OW/OB, exhibit behaviors and perceptions susceptible to weight gain, and more often be underestimated in their weight status by their mothers than girls. After adjusting for child age, maternal education and weight status, household income and urban/rural residence, we found that the influence of adverse behaviours and perceptions on childhood OW/OB was stronger in boys than girls.

In our study, the sex difference in OW/OB rate was significant in the adolescent group, but not in the younger group. Both boys and girls experience significant physical and psychological changes in adolescence, during which their self-identity and body begin to mature ${ }^{(22)}$. The adolescents' behaviours and perceptions are often reflective of their values that are shaped by their increasing understanding of the world throughout puberty, and generally differ by sex. For example, girls are more likely to be more 'cooperative and prosocial' and consequently to pursue social approval ${ }^{(23)}$. On the other hand, boys are more likely oriented by 'status-oriented goals', which tend to cultivate 'aggressive, self-promoting behavior' ${ }^{\text {(23). As }}$ shown in our findings, the sex differences in adolescent weight-related beliefs and behaviours were significant and consistent with those reported in other China-based studies $^{(11,24,25)}$. For example, a study on Chinese teenagers $^{(11)}$ reported that non-overweight girls were more 
likely than boys to self-perceive as overweight while normal-to-overweight boys were more likely than girls to self-perceive as overweight. Girls who self-perceived as overweight were more likely to experience mental distress symptoms than boys ${ }^{(25)}$. The preferences of girls for thinness and boys for muscular features likely relate to the modelling of specific body images portrayed by Chinese mass media ${ }^{(24,26,27)}$. Obesity intervention programmes should consider sex differences in Chinese environmental cues to prevent biased weight-related beliefs and behaviours among boys and girls.

Coupled with children's sex difference in self-perceived weight, mothers' weight status and perception of the child's weight also differed by child sex. More OW/OB boys than OW/OB girls were likely to have OW/OB mothers, but mothers being normal- or underweight were not associated with the sex difference in childhood obesity. Studies of both developing and developed countries have identified parental obesity to be one of the risk factors for childhood obesity ${ }^{(28,29)}$. Boys' mothers were more likely to underestimate their child's weight status than girls' mothers $(24.4 \%$ of boys $v .10 \cdot 3 \%$ of girls), while girls' mothers were more likely to accurately identify their child's weight status than boys' mothers $(72 \cdot 4 \%$ of girls $v$. $67.4 \%$ of boys). It is interesting to note that girls' mothers were more likely than boys' mothers to be consistent with their daughters in perceiving the child's overweight (11.6\% of girls' mothers $v .6 .6 \%$ of boys' mothers). Bauer et al. suggest that parents are a critical source of modelling in dietary intake behaviour for adolescent girls ${ }^{(30)}$, which could help explain the consistency in overweight perception by the mothers and the daughters. Our results also confirm the previous findings where parental obesity is related to childhood obesity and that parenting is associated with children's behaviours and perceptions about their own weight that differed by child sex.

In addition, we found that sex difference in the OW/OB outcome was more prevalent among children with lower SES (i.e. mothers with up to a high school degree and with low household income) and those who lived in urban areas. Higher SES in our study was associated with higher OW/OB prevalence, but sex difference in childhood OW/OB was significant only among the lower SES group. While obesity is known to be associated with individual choices to consume an energy-dense diet and decreased physical activity independent of SES ${ }^{(31)}$, parents of low SES may prefer sons to daughters, be more likely to underestimate boys' weight, and provide more energy-dense foods to sons compared with daughters. A study using school-based nationally representative data also observed a similar trend in such sex disparity by residence area. While rural areas in developed countries are more likely to have OW/OB children than urban areas ${ }^{(32,33)}$, China and other developing Asian countries have higher childhood OW/OB rate in urban areas along with rapid urbanization ${ }^{(34,35)}$. The lifestyle and environmental risks that come with urbanization include increased access to high-fat and animal-based foods, reduced air and water quality, and mental stress ${ }^{(36-38)}$ that are considered obesogenic factors. This urban-obesogenic association aligns with our findings where behaviours that promote excessive weight gain are more common in boys than in girls. Further studies to examine the association of economic stability and residence with values around and perception towards sex differences would benefit urban planning, to incorporate sex differences as a critical element of healthy residence in urban areas.

To our knowledge, the present study was the first to include diverse risk factors regarding individual, parental and familial characteristics to examine the reasons for sex differences in childhood obesity in China. We found that boys had larger associations of self-motivation in weight management and of self- and maternal perception of child overweight with the risk of childhood obesity than girls. Our results suggest that mothers are more inclined to overlook OW/OB status in their sons than their daughters. We could not verify the causal relationship of underperception of weight status and less motivation in weight management with a higher risk of childhood obesity among boys than girls in the present study due to the cross-sectional design. A longitudinal study will help confirm whether boys' undesirable weight perception and less attempt to manage healthy weight cause a sex difference in follow-up childhood obesity.

The current study has some limitations. Given its crosssectional nature, we cannot infer causality. Also, several key variables on energy balance, such as time spent on physical activity, had substantial missing data, which prevented an in-depth investigation of energy expenditure. However, the study has several strengths. First, we used data collected from a large nationwide survey, which included nine provinces and three megacities. Specifically, the data represent both rural and urban residents and reflect urbanicity in China as one of the risk factors contributing to childhood obesity. Second, we examined both child and maternal perceptions on child weight status and related behaviours for the comprehensive analysis of risk factors in childhood obesity.

\section{Conclusion}

In conclusion, while sex difference is a result of genetic variation, one's acquired behaviours and perceptions, often shaped by unique experiences at the individual, parental and familial levels, these factors can be modified through education and changes in external factors. Adolescence is a critical period in developing healthful behaviours and values that prevent childhood and likely adult obesity and related health outcomes. Future childhood obesity prevention efforts should consider the sex disparity in individual, parental and familial factors through building healthy body images among children and their parents. 


\section{Acknowledgements}

Acknowledgements: The authors thank Dr Paula Vincent for her assistance in improving the manuscript. Financial support: The study was supported by the National Institutes of Health (NIH), National Institute of Child Health and Human Development (NICHD) (grant number U54HD070725). The U54 project is co-funded by the NICHD and the Office of Behavioral and Social Sciences Research (OBSSR), NIH; Y.W. is the principal investigator. The content is solely the responsibility of the authors and does not necessarily represent the official views of the funders. Conflict of interest: No conflict of interest was declared. Authorship: Y.W. and V.H.C.W. conceived the study, designed the model, analysed the data and drafted the manuscript. J.M. analysed data and drafted the manuscript. Y.W. directed the study and provided administrative support. All authors contributed to data analysis, results interpretation and manuscript revision. Ethics of buman subject participation: The present study was approved by the University at Buffalo Institutional Review Board.

\section{References}

1. Li XY, Jiang $\mathrm{Y}, \mathrm{Hu} \mathrm{N}$ et al. (2012) Prevalence and characteristic of overweight and obesity among adults in China, 2010. Zhonghua Yu Fang Yi Xue Za Zhi 46, 683-686.

2. Nishtar S, Gluckman P \& Armstrong T (2016) Ending childhood obesity: a time for action. Lancet 387, 825-827.

3. Wabitsch M, Moss A \& Kromeyer-Hauschild K (2014) Unexpected plateauing of childhood obesity rates in developed countries. BMC Med 12, 17.

4. Popkin BM, Adair LS \& Ng SW (2012) Global nutrition transition and the pandemic of obesity in developing countries. Nutr Rev 70, 3-21.

5. Sun H, Ma Y, Han D et al. (2014) Prevalence and trends in obesity among China's children and adolescents, 1985-2010. PLoS Med 9, e105469.

6. Ji CY \& Cheng TO (2009) Epidemic increase in overweight and obesity in Chinese children from 1985 to 2005. Int J Cardiol 132, 1-10.

7. Ji CY \& Chen TJ; Working Group on Obesity in China (2013) Empirical changes in the prevalence of overweight and obesity among Chinese students from 1985 to 2010 and corresponding preventive strategies. Biomed Environ Sci 26, 1-12.

8. Wells JC (2007) Sexual dimorphism of body composition. Best Pract Res Clin Endocrinol Metab 21, 415-430.

9. Wardle J, Haase AM, Steptoe A et al. (2004) Gender differences in food choice: the contribution of health beliefs and dieting. Ann Behav Med 27, 107-116.

10. Fan Y, Li Y, Liu A et al. (2010) Associations between body mass index, weight control concerns and behaviors, and eating disorder symptoms among non-clinical Chinese adolescents. BMC Public Health 10, 314.

11. Xie B, Chou CP, Spruijt-Metz D et al. (2006) Weight perception and weight-related sociocultural and behavioral factors in Chinese adolescents. Prev Med 42, 229-234.
12. Li J, Lei J, Wen S et al. (2014) Sex disparity and perception of obesity/overweight by parents and grandparents. Paediatr Child Health 19, e113-e116.

13. Xie B, Chou CP, Spruijt-Metz D et al. (2006) Weight perception, academic performance, and psychological factors in Chinese adolescents. Am J Health Behav 30, $115-124$.

14. Zhang B, Zhai FY, Du SF et al. (2014) The China Health and Nutrition Survey, 1989-2011. Obes Rev 15, Suppl. 1, 2-7.

15. US Department of Health and Human Services \& US Department of Agriculture (2016) Dietary Guidelines for Americans 2015-2020, 8th ed. Washington, DC: DHHS \& USDA.

16. Cole TJ, Bellizzi MC, Flegal KM et al. (2000) Establishing a standard definition for child overweight and obesity worldwide: international survey. BMJ 320, 1240-1243.

17. Kuczmarski RJ, Ogden CL, Grummer-Strawn LM et al. (2000) CDC growth charts: United States. Adv Data issue $314,1-27$.

18. Zhai F-Y, Guo X, Popkin BM et al. (1996) Evaluation of the 24-hour individual recall method in china. Food Nutr Bull 17, 154-161.

19. Chinese Nutrition Society. (2013) Chinese DRIs Handbook. http://www.cnsoc.org/drpostand/ (assessed February 2015).

20. Liu X, Liu L, Owens JA et al. (2005) Sleep patterns and sleep problems among schoolchildren in the United States and China. Pediatrics 115, Suppl. 1, 241-249.

21. Zhou BF, \& Cooperative Meta-Analysis Group of the Working Group on Obesity in China (2002) Predictive values of body mass index and waist circumference for risk factors of certain related diseases in Chinese adults - study on optimal cut-off points of body mass index and waist circumference in Chinese adults. Biomed Environ Sci 15, 83-96.

22. Christie D \& Viner R (2005) Adolescent development. BMJ 330, 301-304

23. Rose AJ \& Rudolph KD (2006) A review of sex differences in peer relationship processes: potential trade-offs for the emotional and behavioral development of girls and boys. Psychol Bull 132, 98-131.

24. Xu X, Mellor D, Kiehne M et al. (2010) Body dissatisfaction, engagement in body change behaviors and sociocultural influences on body image among Chinese adolescents. Body Image 7, 156-164.

25. Xie B, Chou CP, Spruijt-Metz D et al. (2011) Longitudinal analysis of weight perception and psychological factors in Chinese adolescents. Am J Health Behav 35, 92-104.

26. Jackson T, Jiang C \& Chen H (2016) Associations between Chinese/Asian versus Western mass media influences and body image disturbances of young Chinese women. Body Image 17, 175-183.

27. Bandura A (2004) Health promotion by social cognitive means. Health Educ Behav 31, 143-164.

28. Davis MM, McGonagle K, Schoeni RF et al. (2008) Grandparental and parental obesity influences on childhood overweight: implications for primary care practice. $\mathrm{J} \mathrm{Am}$ Board Fam Med 21, 549-554.

29. Andegiorgish AK, Wang J, Zhang X et al. (2012) Prevalence of overweight, obesity, and associated risk factors among school children and adolescents in Tianjin, China. Eur J Pediatr 171, 697-703.

30. Bauer KW, Neumark-Sztainer D, Fulkerson JA et al. (2011) Familial correlates of adolescent girls' physical activity, television use, dietary intake, weight, and body composition. Int J Behav Nutr Phys Act 8, 25.

31. Wang Y \& Lim H (2012) The global childhood obesity epidemic and the association between socioeconomic status and childhood obesity. Int Rev Psychiatry 24, 176-188. 
32. Johnson JA 3rd \& Johnson AM (2015) Urban-rural differences in childhood and adolescent obesity in the United States: a systematic review and meta-analysis. Child Obes 11, 233-241.

33. Bertoncello C, Cazzaro R, Ferraresso A et al. (2008) Prevalence of overweight and obesity among school-aged children in urban, rural and mountain areas of the Veneto Region, Italy. Public Health Nutr 11, 887-890.

34. Angkurawaranon C, Jiraporncharoen W, Chenthanakij B et al. (2014) Urban environments and obesity in southeast Asia: a systematic review, meta-analysis and meta-regression. PLoS One 9, e113547.
35. Do LM, Tran TK, Eriksson B et al. (2015) Preschool overweight and obesity in urban and rural Vietnam: differences in prevalence and associated factors. Glob Health Action 8, 28615.

36. Gong P, Liang S, Carlton EJ et al. (2012) Urbanisation and health in China. Lancet 379, 843-852.

37. Chen J, Chen S \& Landry PF (2015) Urbanization and mental health in China: linking the 2010 population census with a crosssectional survey. Int J Environ Res Public Health 12, 9012-9024.

38. Zhang J, Wang D, Eldridge AL et al. (2017) Urban-rural disparities in energy intake and contribution of fat and animal source foods in Chinese children aged 4-17 years. Nutrients 9, E526. 